\title{
Rancang Bangun Mesin Peniris Minyak
}

\author{
Irdam $^{1}$, Dani Setiawan ${ }^{2}$, Ade Irmayanti $^{3}$, Aditya $^{4}$ \\ ${ }^{1,2,3,4}$ Perawatan dan Perbaikan Mesin, Akademi Teknik Soroako, Indonesia \\ 2dani@ats-sorowako.ac.id
}

\begin{abstract}
ABSTRAK
Penirisan minyak pada makanan gorengan secara tradisional dipandang kurang optimal. Selain membutuhkan waktu yang lebih lama namun, kadar minyak yang dikandung makanan masih relatif tinggi sehingga makanan menjadi kurang awet. Penelitian ini bertujuan merancang dan membangun sebuah prototipe mesin peniris minyak dengan sistem rotari yang memanfaatkan gaya sentrifugal yang mampu melakukan penirisan minyak secara lebih cepat dengan hasil yang lebih baik dibandingkan dengan cara tradisional. Kelebihan rancangan mesin peniris minyak dalam penelitian ini adalah dalam hal portabilitas, kemudahan untuk membersihkan tabung peniris karena dapat dibongkar pasang, dan pengeluaran makanan dari tabung peniris menggunakan pedal. Tahapan pembuatan mesin ini terdiri atas tahap perancangan, manufaktur, perakitan dan pengujian mesin. Mesin dirancang dan dibangun dengan spesifikasi: tinggi $1155 \mathrm{~mm}$, panjang $945 \mathrm{~mm}$, dan lebar $600 \mathrm{~mm}$. Hasil uji coba penirisan keripik dan kacang goreng menunjukkan bahwa penirisan menggunakan mesin peniris minyak terbukti lebih efektif dibandingkan penirisan secara tradisional. Penirisan keripik menggunakan mesin dengan kecepatan putaran $500 \mathrm{rpm}$ selama 1 menit menghasilkan pengurangan massa sebesar $4,5 \%$, sedangkan penirisan tradisional hanya menghasilkan pengurangan massa sebesar $1,8 \%$. Penirisan kacang goreng menggunakan mesin selama 1 menit menghasilkan pengurangan massa sebesar $0,91 \%$, sedangkan penirisan tradisional hanya menghasilkan pengurangan massa sebesar $0,45 \%$. Untuk kacang goreng dibutuhkan waktu 5 menit agar diperoleh pengurangan massa sebesar $1,8 \%$.
\end{abstract}

Kata kunci: mesin peniris minyak, makanan ringan, keripik, kacang goreng, gaya sentrifugal, sistem rotari

\section{ABSTRACT}

Design and Construction of Deoiling Machine. Traditionally removing oil from fried snacks is considered less than optimal. In addition to longer time requirement, the oil content of the snacks is still relatively high which makes the snacks less preservable. This research aims to design and build a prototype of deoiling machine with a rotary system that utilizes centrifugal force to remove oil faster with better results than the traditional method. The advantages of our machine design is in terms of portability, ease of cleaning the inner rotating drum since it is detachable, and discharging the drum's content using a pedal. The stages of building this machine consist of designing, manufacturing, assembling and testing the machine. The machine is designed and built with the following specifications: height 1155 $\mathrm{mm}$, length $945 \mathrm{~mm}$, and width $600 \mathrm{~mm}$. The test results for chips and fried peanuts showed that deoiling using the machine was more effective than traditional oil removal. Deoiling chips using the machine with a rotating speed of 500 rpm for 1 minute results in a 4.5\% reduction in mass, while traditional oil removal results in a $1.8 \%$ reduction in mass. Deoiling fried beans using the machine for 1 minute results in a $0.91 \%$ reduction in mass, whereas traditional oil removal only results in a $0.45 \%$ reduction in mass. It took 5 minutes of deoiling for fried beans to lose $1.8 \%$ of its original mass.

Keywords: deoiling machine, snacks, chips, fried beans, centrifugal force, rotary system

\section{PENDAHULUAN}

Berdasarkan data Statistik Konsumsi Pangan tahun 2018 dari Pusat Data dan Sistem Informasi Pertanian, Kementerian Pertanian RI, rata-rata pertumbuhan konsumsi per kapita makanan gorengan dalam rentang tahun 2014-2018 adalah sebesar 15,083\% [1]. Peningkatan daya saing masyarakat Indonesia dalam bidang industri, khususnya industri kecil berskala rumah tangga, memerlukan pengembangan sarana atau peralatan yang dapat membantu dalam proses pengolahan produk industri rumah tangga tersebut. Dalam produksi makanan ringan seperti kerupuk dan kacang telur, proses penirisan makanan tersebut masih menggunakan cara tradisional, yaitu ditiriskan 
secara alami dengan diletakkan dalam wadah dari anyaman bambu atau dari kawat strimin kemudian diangin-anginkan [5][6]. Produksi makanan ringan menggunakan mesin peniris minyak mampu memberikan hasil berkali lipat dibandingkan dengan cara tradisional. Percobaan menunjukkan bahwa penirisan makanan ringan hasil gorengan seperti kacang telur dengan cara tradisional membutuhkan waktu yang lebih lama namun produk kurang awet karena kandungan minyaknya yang relatif masih tinggi [2][3][4][5].

Akan tetapi, pengeluaran makanan yang sudah tertiriskan pada sebagian besar mesin yang ada masih dengan cara menumpahkan makanan dari dalam tabung peniris. Hal inilah yang mendorong kami untuk ikut mengembangkan mesin penirisan minyak yang lebih memudahkan pengguna. Kelebihan rancangan mesin peniris minyak dalam penelitian ini adalah dalam hal portabilitas, kemudahan untuk membersihkan tabung peniris karena dapat dibongkar pasang, dan pengeluaran makanan dari tabung peniris menggunakan pedal. Karya ini juga bertujuan menunjukkan perbandingan hasil penirisan secara tradisional dengan hasil penirisan menggunakan mesin peniris minyak ini.

\section{METODE}

\section{A. Tahapan Rancang Bangun Mesin}

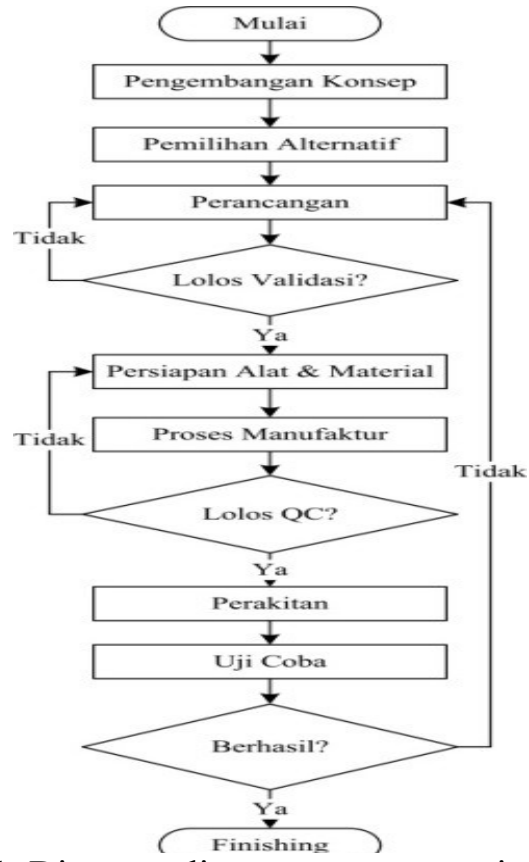

Gambar 1. Diagram alir perancangan mesin peniris minyak
Tahap perancangan meliputi sketsa mesin, spesifikasi teknik, perhitungan, dan berbagai alternatif komponen yang dapat diterapkan pada mesin tersebut. Tahap perancangan dimulai dari pengembangan konsep dengan mempelajari mesinmesin yang sudah ada. Data dan informasi yang diperoleh kemudian dianalisis untuk menghasilkan suatu rancangan, daftar tuntutan, alternatif rancangan, dan pemilihan rancangan yang sesuai. Gambar rancangan mesin awal disesuaikan dengan hasil perhitungan. Tahapan rancang bangun mesin ditunjukkan oleh diagram alir pada gambar 1 .

Hasil rancang bangun penelitian ini adalah mesin peniris minyak seperti yang diperlihatkan pada gambar 2. Mesin peniris minyak dirancang dan dibangun dengan kapasitas 30 liter, dengan konstruksi yang lebih sederhana dan bobot mesin yang lebih ringan agar lebih mudah dipindahkan (portabel). Tabung peniris dirancang dengan pengikatan pada poros pemutar yang menggunakan baut sehingga tabung peniris dapat dibongkar pasang untuk dibersihkan. Pengeluaran makanan yang sudah tertiriskan dilakukan menggunakan pedal.

Pada prototipe mesin ini, tabung peniris masih menggunakan material aluminium. Pada umumnya, baja tahan karat digunakan dalam mesin-mesin pengolah makanan. Namun dalam pembuatan prototipe ini, aluminium digunakan sebagai material tabung peniris karena selain sulit didapatkan di daerah Luwu Timur, baja tahan karat juga membutuhkan biaya yang lebih tinggi. Meskipun demikian, poros utama untuk menopang tabung peniris dan tabung luar dibuat dari baja tahan karat.

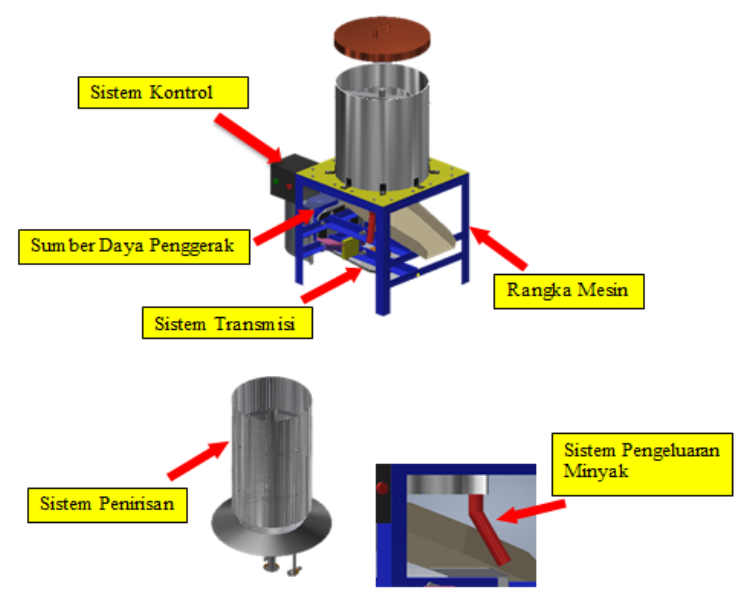

Gambar 2. Rancangan mesin peniris minyak 
Mesin ini menggunakan tenaga penggerak berupa motor listrik 1 fase berdaya $0,5 \mathrm{HP}$ dengan kecepatan putaran maksimal 1300 rpm. Sistem transmisi pada mesin ini terdiri atas poros pemutar di mana tabung peniris dipasang, puli dan sabuk, blok bantalan dan pasak yang berfungsi untuk meneruskan putaran dari motor listrik ke tabung peniris. Putaran yang dihasilkan motor listrik diteruskan melalui sistem transmisi mesin, yaitu puli dan sabuk, ke poros utama mesin yang tersambung langsung dengan tangkai pemutar tabung peniris. Pembuatan poros dilakukan dengan mesin bubut dan pembuatan pasak dilakukan dengan mesin milling. Sementara itu, sistem kontrol mesin peniris minyak berfungsi untuk mengontrol kerja mesin.

Saat motor listrik dihidupkan, putaran dari motor listrik akan diteruskan melalui sistem transmisi puli dan sabuk ke poros pemutar. Tabung peniris yang terikat pada poros pemutar akan ikut berputar. Pada saat tabung peniris, yang berisi makanan ringan seperti keripik dan kacang goreng, berputar dengan kecepatan tinggi, minyak yang terkandung dalam makanan akan terlempar keluar melalui lubanglubang kecil yang terdapat pada sisi tabung peniris. Minyak yang terlempar akan tertampung dalam tabung penampung minyak (tabung luar). Minyak yang tertampung dalam tabung luar kemudian dibuang melalui sebuah pipa pengeluaran. Setelah tertiriskan, makanan akan dikeluarkan melalui lubang pengeluaran makanan yang menggunakan sistem pedal. Saat pedal ditekan, pelat kerucut penutup lubang akan terdorong naik sehingga makanan akan jatuh melalui lubang pengeluaran tersebut. Makanan yang keluar akan ditadah oleh talang sehingga makanan dapat keluar mengikuti arah keluaran talang.

B. Spesifikasi Bagian-bagian Mesin

Tabel 1. Dimensi bagian-bagian mesin

\begin{tabular}{l|l}
\hline \multicolumn{1}{c|}{ Bagian Mesin } & \multicolumn{1}{c}{ Dimensi } \\
\hline Kapasitas tabung peniris & $30 \mathrm{~L}$ \\
Motor listrik & $0,5 \mathrm{HP}$ \\
Putaran motor $\left(n_{1}\right)$ & $1300 \mathrm{rpm}$ \\
Putaran mesin $\left(n_{2}\right)$ & $500 \mathrm{rpm}$ \\
Diameter puli $1\left(d_{1}\right)$ & $76 \mathrm{~mm}$ \\
Diameter puli 2 $\left(d_{2}\right)$ & $198 \mathrm{~mm}$ \\
Jarak antara sumbu poros & $400 \mathrm{~mm}$ \\
Diameter poros mesin & $32 \mathrm{~mm}$ \\
Tabung luar & $\varnothing 460 \mathrm{~mm} \times 600 \mathrm{~mm}$ \\
Tabung peniris & $\varnothing 300 \mathrm{~mm} \times 420 \mathrm{~mm}$ \\
\hline
\end{tabular}

\section{Perhitungan Volume Tabung}

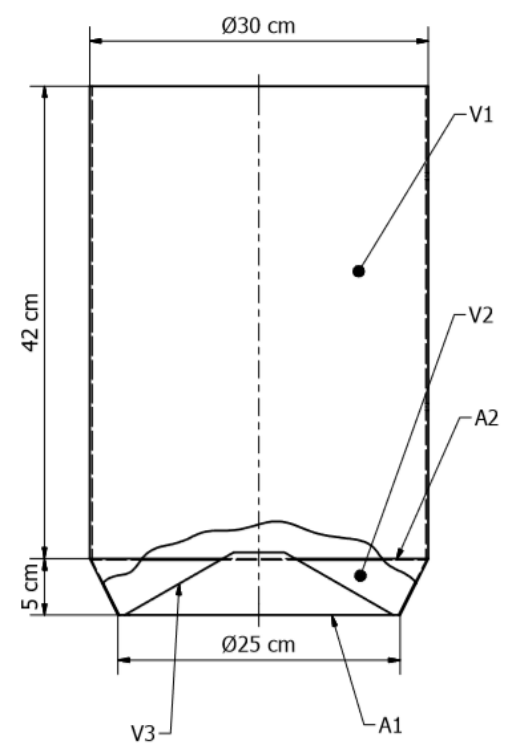

Gambar 3. Tabung peniris

Tabung peniris dirancang agar dapat menampung makanan dengan volume $30 \mathrm{~L}$. Berdasarkan gambar 3 , volume bagian tabung peniris yang berbentuk silinder adalah

$$
\begin{aligned}
V_{1} & =\frac{1}{4} \pi d_{a}^{2} h \\
& =\frac{1}{4} \pi \cdot(30 \mathrm{~cm})^{2} \cdot 42 \mathrm{~cm} \approx 29688 \mathrm{~cm}^{3}
\end{aligned}
$$

Volume bagian bawah tabung peniris yang berbentuk kerucut terpancung adalah

$$
\begin{aligned}
V_{2} & =\frac{1}{12} \pi h\left(d_{a}^{2}+d_{b}^{2}+d_{a} d_{b}\right) \\
& =\frac{1}{12} \pi \cdot 5 \mathrm{~cm} \cdot\left(\begin{array}{c}
(30 \mathrm{~cm})^{2}+(25 \mathrm{~cm})^{2} \\
+(30 \mathrm{~cm}) \cdot(25 \mathrm{~cm})
\end{array}\right) \\
& \approx 2978 \mathrm{~cm}^{3}
\end{aligned}
$$

Volume kerucut penutup lubang adalah

$$
V_{3}=\frac{1}{12} \pi d_{c}^{2} h
$$




$$
=\frac{1}{12} \pi \cdot(24,2 \mathrm{~cm})^{2} \cdot 6 \mathrm{~cm} \approx 920 \mathrm{~cm}^{3}
$$

Dengan demikian, volume tabung peniris yang dapat menampung makanan adalah

$V=V_{1}+V_{2}-V_{3}=31746 \mathrm{~cm}^{3} \approx 31,7 \mathrm{~L}$

\section{Perhitungan Puli dan Sabuk [5][6]}

1. Diameter puli 2:

$d_{2}=\frac{n_{1}}{n_{2}} d_{1}=\frac{1300 \mathrm{rpm}}{500 \mathrm{rpm}} \cdot 76 \mathrm{~mm} \approx 198 \mathrm{~mm}$

Rasio $d_{1}: d_{2}=1: 2,6$

2. Panjang sabuk dengan jarak sumbu poros $C=400 \mathrm{~mm}$ :

$$
\begin{aligned}
L= & 2 C+\frac{\pi}{2}\left(d_{1}+d_{2}\right)+\frac{1}{4 C}\left(d_{2}-d_{1}\right)^{2} \\
= & 2 \cdot 400 \mathrm{~mm}+\frac{\pi}{2}(76 \mathrm{~mm}+198 \mathrm{~mm}) \\
& +\frac{1}{4.400 \mathrm{~mm}}(198 \mathrm{~mm}-76 \mathrm{~mm})^{2} \\
\approx & 1239,7 \mathrm{~mm} \approx 49^{\prime \prime}(\text { A } 47)
\end{aligned}
$$

3. Jarak antara sumbu poros:

$$
\begin{aligned}
b & =2 L-\pi\left(d_{1}+d_{2}\right) \\
& =2 \cdot 1239,7 \mathrm{~mm}-\pi(76 \mathrm{~mm}+198 \mathrm{~mm}) \\
& \approx 1618,6 \mathrm{~mm}
\end{aligned}
$$$$
C=\frac{b+\sqrt{b^{2}-8\left(d_{2}-d_{1}\right)^{2}}}{8} \approx 400 \mathrm{~mm}
$$

4. Kecepatan linear sabuk:

$$
\begin{aligned}
v & =\pi d_{1} n_{1}=\frac{\pi \cdot 76 \mathrm{~mm} \cdot 1300 \mathrm{rpm}}{60 \mathrm{~s} / \text { menit } \cdot 1000 \mathrm{~mm} / \mathrm{m}} \\
& \approx 5,2 \mathrm{~m} / \mathrm{s}
\end{aligned}
$$

\section{E. Perhitungan Poros Utama}

Selanjutnya dilakukan perhitungan-perhitungan berikut ini untuk menentukan diameter poros minimum.

1. Daya motor listrik:

$$
P \approx 0,5 \mathrm{HP} \cdot 746 \mathrm{~W} / \mathrm{HP}=373 \mathrm{~W}
$$

2. Torsi motor listrik:

$P_{\text {motor }}=\omega T_{\text {motor }}=2 \pi n T_{\text {motor }}$

$373 \mathrm{~W}=\frac{2 \pi \cdot 1300 \mathrm{rpm}}{60 \mathrm{~s} / \mathrm{menit}} T_{\text {motor }}$

$T_{\text {motor }} \approx 2,74 \mathrm{~N} \mathrm{~m}=2740 \mathrm{~N} \mathrm{~mm}$

3. Momen puntir pada puli 1 dengan faktor pemakaian $C_{B}=1$ :

$$
\begin{aligned}
M_{p 1} & =\frac{C_{B} P}{n} \\
& =\frac{1 \cdot 373 \mathrm{~W}}{1300 \mathrm{rpm}} \cdot \frac{1}{2 \pi} \cdot \frac{60 \mathrm{~s}}{1 \mathrm{menit}} \cdot \frac{1000 \mathrm{~mm}}{1 \mathrm{~m}} \\
& \approx 2740 \mathrm{~N} \mathrm{~mm}
\end{aligned}
$$

4. Gaya keliling (gaya tangensial) pada puli 1:

$$
F_{u 1}=\frac{2 M_{p 1}}{d_{1}}=\frac{2 \cdot 2740 \mathrm{~N} \mathrm{~mm}}{76 \mathrm{~mm}} \approx 72,1 \mathrm{~N}
$$

5. Momen puntir pada puli 2:

$$
\begin{aligned}
M_{p 2} & =M_{p 1} \frac{d_{1}}{d_{2}}=2740 \mathrm{~N} \mathrm{~mm} \cdot \frac{76 \mathrm{~mm}}{198 \mathrm{~mm}} \\
& \approx 1051,72 \mathrm{~N} \mathrm{~mm}
\end{aligned}
$$

6. Gaya keliling pada puli 2:

$F_{u 2}=\frac{2 M_{p 2}}{d_{2}}=\frac{2 \cdot 1051,72 \mathrm{~N} \mathrm{~mm}}{198 \mathrm{~mm}} \approx 10,623 \mathrm{~N}$

7. Gaya normal minimum yang terjadi pada puli yang diakibatkan putaran dari motor listrik dengan koefisien gesekan antara puli dengan sabuk sebesar $\mu=0,5$ :

$F_{N}=\frac{F_{r}}{\mu}=\frac{F_{u 2}}{\mu}=\frac{10,623 \mathrm{~N}}{0.5} \approx 21,25 \mathrm{~N}$

8. Poros menggunakan material baja tahan karat dengan tegangan bengkok ijin poros $\sigma_{b, i j}=$ 
$68 \mathrm{~N} / \mathrm{mm}^{2}$. Gaya-gaya reaksi pada tumpuan diperlihatkan pada gambar 4 , diagram benda bebasnya diperlihatkan pada gambar 5 .

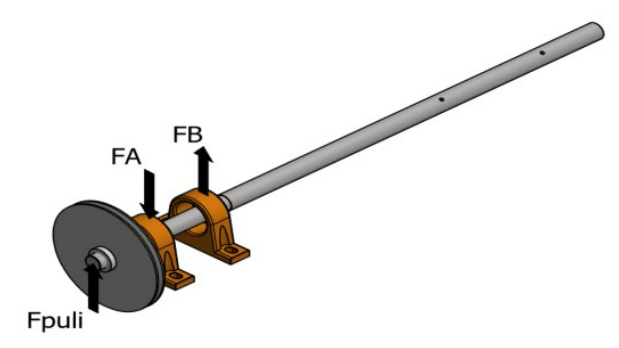

Gambar 4. Diagram konstruksi poros utama

Diagram benda bebas (DBB):

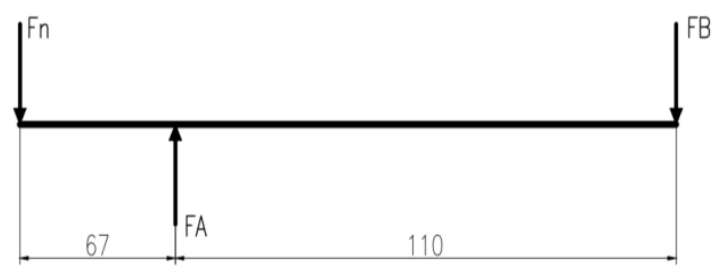

Gambar 5. Diagram gaya sumbu $x$

9. Gaya-gaya reaksi pada tumpuan ditentukan menggunakan syarat kesetimbangan statis sebagai berikut:

$$
\begin{aligned}
& \sum M_{B}=0 \\
& F_{A} \cdot 110 \mathrm{~mm}-F_{N} \cdot 177 \mathrm{~mm}=0 \\
& F_{A} \cdot 110 \mathrm{~mm}-21,25 \mathrm{~N} \cdot 177 \mathrm{~mm}=0 \\
& F_{A}=\frac{3761,25 \mathrm{~N} \mathrm{~mm}}{110 \mathrm{~mm}} \approx 34,19 \mathrm{~N} \\
& \sum F_{y}=0 \\
& F_{A}-F_{N}-F_{B}=0 \\
& 34,19 \mathrm{~N}-21,25 \mathrm{~N}-F_{B}=0 \\
& F_{B}=12,94 \mathrm{~N}
\end{aligned}
$$

10. Diagram gaya dan diagram momen sumbu $x$

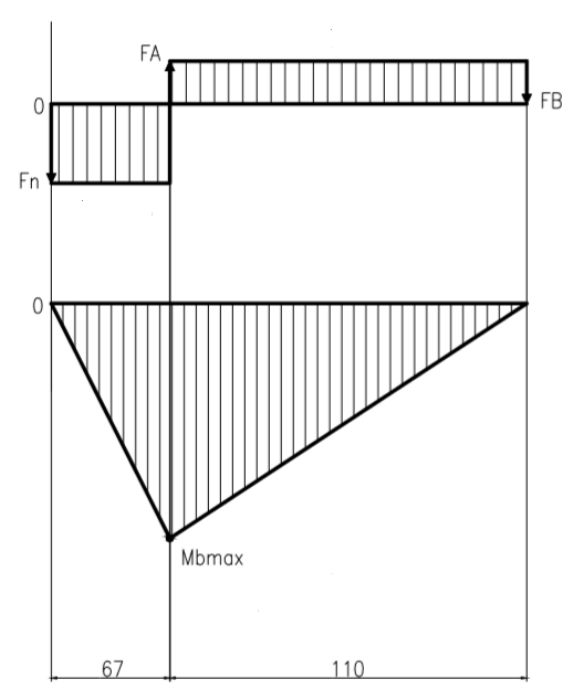

Gambar 6. Diagram gaya dan momen sumbu x

Dari diagram pada gambar 6 diperoleh momen bengkok maksimum sebesar $M_{b, \text { maks }}=F_{N} \ell=$ $21,25 \mathrm{~N} \cdot 67 \mathrm{~mm} \approx 1423,75 \mathrm{~N} \mathrm{~mm}$.

11. Momen gabungan dari momen bengkok dan momen puntir:

$$
\begin{aligned}
M_{R} & =\sqrt{M_{b, \text { maks }}^{2}+0,75\left(\alpha_{0} M_{p}\right)^{2}} \\
& =\sqrt{(1423,75)^{2}+0,75(0,75 \cdot 2740)^{2}} \\
& \approx 2279,1 \mathrm{~N} \mathrm{~mm}
\end{aligned}
$$

12. Tegangan bengkok ijin pada poros dengan faktor penurun tegangan sebesar $\beta_{k}=1,7$ :

$$
\sigma_{b, i j \prime}=\frac{\sigma_{b, i j}}{\beta_{k}}=\frac{68 \mathrm{~N} / \mathrm{mm}^{2}}{1,7}=40 \mathrm{~N} / \mathrm{mm}^{2}
$$

13. Diameter poros minimum:

$$
\begin{aligned}
d & =\sqrt[3]{\frac{M_{R}}{0,1 \sigma_{b, i j^{\prime}}}}=\sqrt[3]{\frac{2279,1 \mathrm{~N} \mathrm{~mm}}{0,1 \cdot 40 \mathrm{~N} / \mathrm{mm}^{2}}} \\
& \approx 8,3 \mathrm{~mm}
\end{aligned}
$$


Karena poros yang digunakan berdiameter 32 $\mathrm{mm}$ berarti konstruksi sangat aman.

\section{F. Pengujian Mesin Peniris Minyak}

Percobaan oleh Romiyadi memperlihatkan bahwa semakin lama waktu penirisan dengan mesin atau semakin tinggi kecepatan putaran tabung peniris, semakin banyak kandungan minyak yang dapat terbuang, namun tidak membandingkannya dengan hasil penirisan secara tradisional [7]. Dalam penelitian ini dibandingkan antara hasil penirisan secara tradisional dan hasil penirisan menggunakan mesin. Makanan ringan yang digunakan pada uji penirisan minyak adalah keripik dan kacang goreng dengan massa awal masing-masing sebesar 1100 gram. Data persentase pengurangan massa masingmasing makanan ringan tersebut diambil untuk penirisan secara tradisional dan dengan mesin selama 1 menit dengan kecepatan putaran sebesar $500 \mathrm{rpm}$. Selanjutnya diambil data persentase pengurangan massa kacang goreng untuk penirisan selanjutnya dengan mesin selama 4 menit. Pengujian dilakukan pada tanggal 12 Agustus 2019 di bengkel C, kampus Akademi Teknik Soroako.

\section{HASIL DAN PEMBAHASAN}

\section{Pengujian pada Keripik}

Gambar 7 memperlihatkan grafik data hasil uji penirisan minyak secara tradisional dan dengan menggunakan mesin peniris minyak untuk keripik.

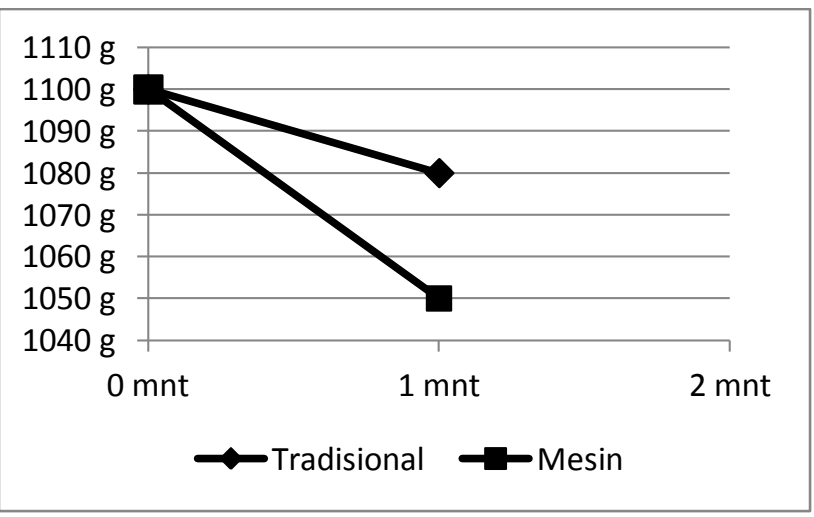

Gambar 7. Pengurangan massa keripik

Pada hasil pengujian penirisan yang dilakukan secara tradisional, massa keripik yang semula 1100 gram menjadi 1050 gram setelah ditiriskan selama 1 menit sehingga diperoleh pengurangan massa sebesar 20 gram atau 1,8\%. Pada hasil pengujian penirisan dengan mesin, massa keripik yang semula 1100 gram berkurang menjadi 1050 gram setelah ditiriskan selama 1 menit sehingga diperoleh pengurangan massa sebesar 50 gram atau $4,5 \%$.

\section{Pengujian pada Kacang Goreng}

Gambar 8 memperlihatkan grafik data hasil uji penirisan minyak secara tradisional dan dengan menggunakan mesin peniris minyak untuk kacang goreng.

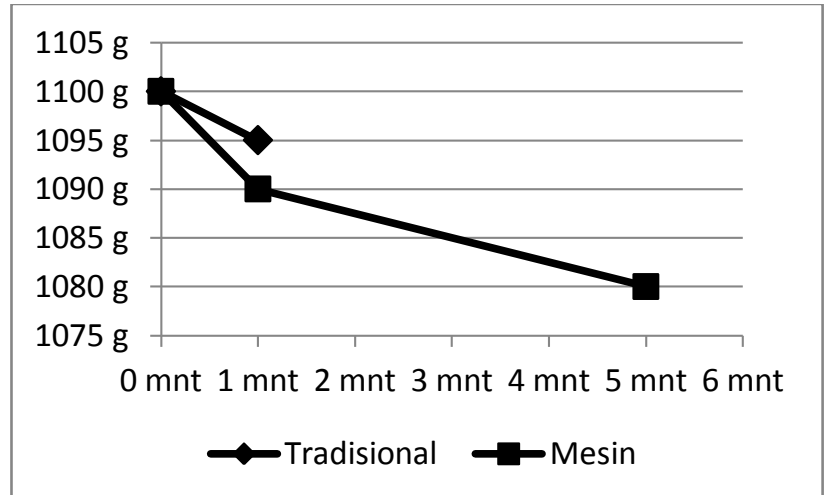

Gambar 8. Pengurangan massa kacang goreng

Pada hasil pengujian penirisan yang dilakukan secara tradisional, massa kacang goreng yang semula 1100 gram berkurang menjadi 1095 gram setelah ditiriskan selama 1 menit sehingga diperoleh pengurangan massa sebesar 5 gram atau $0,45 \%$. Pada hasil pengujian penirisan dengan mesin, massa kacang goreng yang semula 1100 gram berkurang menjadi 1090 gram setelah ditiriskan selama 1 menit sehingga diperoleh pengurangan massa sebesar 10 gram atau $0,91 \%$. Untuk kacang goreng, pengujian dilanjutkan dengan melakukan penirisan dengan mesin selama 4 menit dan diperoleh pengurangan massa lebih lanjut dari massa semula 1090 gram menjadi 1080 gram sehingga diperoleh pengurangan massa sebesar 10 gram atau 0,92\%. Dengan demikian, untuk kacang goreng dibutuhkan waktu 5 menit agar diperoleh pengurangan massa sebesar $1,8 \%$. 


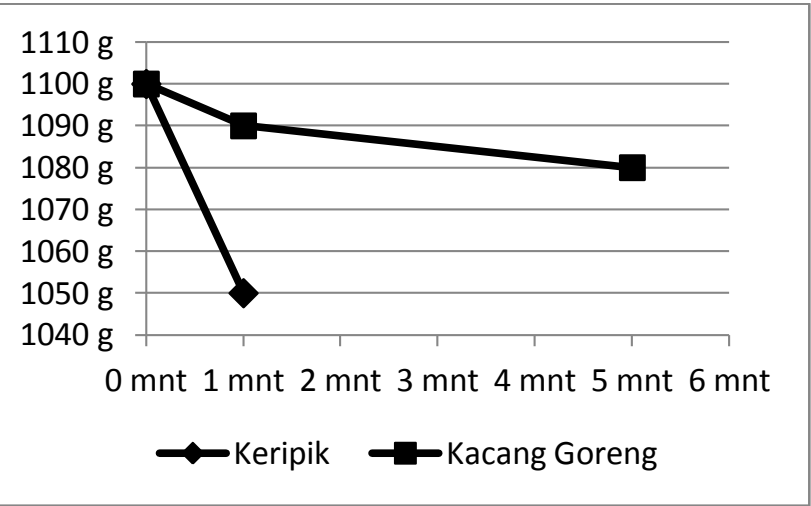

Gambar 9. Hasil penirisan dengan mesin Gambar 9 memperlihatkan grafik data hasil uji penirisan minyak menggunakan mesin peniris untuk keripik dan kacang goreng. Untuk penirisan selama 1 menit, persentase pengurangan massa keripik hampir 5 kali lebih besar dibandingkan persentase pengurangan massa kacang goreng.

\section{KESIMPULAN}

Rancang bangun ini menghasilkan sebuah prototipe mesin peniris minyak berkapasitas 30 liter dengan tabung peniris yang dapat dibongkar pasang. Mesin ini memiliki spesifikasi tinggi $1155 \mathrm{~mm}$, panjang $945 \mathrm{~mm}$, dan lebar $600 \mathrm{~mm}$. Dengan tenaga penggerak berupa motor listrik 1 fase berdaya 0,5 HP (373 watt) dengan kecepatan putaran maksimal $1300 \mathrm{rpm}$ dan sistem transmisi berupa puli berdiameter $76 \mathrm{~mm}$ dan $198 \mathrm{~mm}$ dihasilkan torsi motor listrik sebesar $2740 \mathrm{~N} \mathrm{~mm}$ yang mampu memutar tabung peniris dengan kecepatan putaran 500 rpm. Data pengujian menunjukkan bahwa penirisan dengan mesin peniris minyak mampu memberikan hasil tirisan yang lebih baik dibandingkan penirisan secara tradisional. Dengan putaran $500 \mathrm{rpm}$, persentase pengurangan massa keripik 2,5 kali lebih besar dan persentase pengurangan massa kacang goreng 2 kali lebih besar dibandingkan penirisan secara tradisional. Kemudian, data penirisan kacang goreng selama 1 dan 5 menit mengisyaratkan bahwa secara umum hasil penirisan tidaklah bersifat linear karena semakin lama kandungan minyak dalam makanan semakin berkurang.

\section{DAFTAR PUSTAKA}

[1] W. B. Komalasari, "Statistik Konsumsi Pangan Tahun 2018," Desember 2018. [Online]. Available:

http://epublikasi.setjen.pertanian.go.id/downloa d/file/450-statistik-konsumsi-pangan-tahun2018.

[2] E. N. Prastyanto, "Perencanaan Mesin Peniris Kacang Telur Sistem Tabung Putar dengan Kapasitas 5 kg,” Skripsi.Program Studi Teknik Mesin, Kediri, 2018.

[3] S. Wasisto, I. L. I. Purnama dan P. W. Anggoro, "Perancangan Mesin Peniris untuk Aneka Makanan Ringan Hasil Gorengan," dalam Seminar Nasional Multi Disiplin Ilmu Unisbank 2016, Semarang, 2016.

[4] S. Huda, "Perancangan Mesin Peniris Minyak untuk Kerupuk," Tugas Akhir.Program Studi Teknik Industri, Malang, 2019.

[5] H. Istiqlaliyah, "Perencanaan Mesin Peniris Minyak pada Keripik Nangka dengan Kapasitas 2,5 kg/menit," Nusantara of Engineering, vol. 2, no. 1, 2015.

[6] B. S. Romadloni, "Perancangan Mesin Peniris Minyak pada Kacang Telur," Proyek Akhir.Program Studi Teknik Mesin, Yogyakarta, 2012.

[7] Romiyadi, "Perancangan dan Pembuatan Mesin Peniris Minyak Menggunakan Kontrol Kecepatan," Jurnal Teknik Mesin, vol. 8, no. 1, April 2018. 